\title{
Cabin Depressurization as a Hijacking Mitigation Tactic: A Consumer Perceptions Study
}

\author{
Rian Mehta \\ Florida Institute of Technology \\ Stephen Rice \\ Embry-Riddle Aeronautical University \\ Scott R. Winter and Paul Buza \\ Florida Institute of Technology
}

\begin{abstract}
The security of a commercial airline flight is the primary concern of all parties involved in the aviation industry. The policies and strategies of dealing with terrorist threats have evolved since the attacks of September 11, 2001. The current policy requires that the cockpit door be locked so that the hijackers have no access to the flight controls. A new method has been discussed whereby the pilots depressurize the cabin so as to eliminate the hijacking threat since all the cabin crew and passengers will be rendered unconscious. While there is a risk of possible negative impact on brain cells due to reduced oxygen, medical experts state that the short duration of cabin depressurization in order to mitigate a threat would cause almost no medical harm. 449 participants from the United States completed the study, wherein they were presented with one of two scenarios: a) the traditional scenario of preventing hijackers from accessing the flight controls, and b) an alternative scenario whereby the pilot depressurizes the cabin. The data analysis suggested that participants felt more negatively, and were less willing to fly aboard the cabin depressurization scenario, as compared to the current policy scenario. In addition, it was found the female participants were less willing to fly and felt more negatively about the cabin depressurization scenario as compared to their male counterparts. Lastly, the mediation analyses showed that affect completely mediated the relationship between the pilots' actions and willingness to fly, suggesting that participants were basing their decisions on emotions.
\end{abstract}

While threats to safety and security have existed in aviation since its inception, they have taken on a new form in the last two decades. The first ever aircraft hijacking took place in 1931. Commercial aviation saw a large spike in hijackings during the 1960s between the United States and Cuba, due to the political war going on between the countries (Holden, 1986). While these incidents were classified as air piracy, they were often for the purposes of either monetary gain or gaining asylum and rarely resulted in any loss of life (Landes, 1978). For this reason, there were no major policy amendments or physical changes to the aviation industry. While these situations were an inconvenience and preferably avoided, they did not generate a mass sense of panic in the aviation authorities or the travelling public. This sentiment has since changed within the aviation industry due to the attacks on September 11, 2001.

While aircraft hijackings had caused fatalities in the past, the landscape of the aviation industry's outlook towards hijackings was changed in 2001. The attacks of September 11, 2001, were a turning point for 
aviation. It was the first time a hijacking of an aircraft resulted in said aircraft being used as a weapon of mass destruction (9/11 Commission, 2004). Thousands of people lost their lives in these attacks, which left the industry and the travelling public seemingly afraid to fly suggested by the decrease in air travel. The September-December 2001 period saw a drop in air travel of $20 \%$ in the United States, as compared to the corresponding time frame of 2000 (Blunk, Clark, \& McGibany, 2006).

Among the wide-sweeping changes that were to follow in aviation the world over were structural upgrades and strategic policies on how to deal with these situations should they arise again. A universal standard that seems to have been adopted by most of the airlines worldwide instructs the pilots to ensure the bulletproof cabin door is locked at all times and disallow entrance to any aggressors. This prevents the hijackers from gaining access to the flight controls (Castella, 2015; Jansen, 2015). This, however, does little by way of protection for the passengers in the cabin. While this method seemed to be the best solution to the problem at the time, some alternative procedures may exist. One alternative course of action could require that the pilot, after donning their oxygen masks, depressurize the cabin, thereby reducing the oxygen content and rendering all people on board-including the hijackers-unconscious.

While this does propose a seemingly more effective means of dealing with a hijacking, this new tactic does include potential side effects caused by oxygen deprivation, which can have potentially dangerous physiological ramifications. Since pilots would only need minutes to divert the aircraft and land, it would minimize the amount of time the passengers are exposed to the lack of oxygen, and would potentially have minimal physiological impact on the passengers' health. Conclusive proof that the effects would be minimal does not exist, as it would be unfeasible to carry out an experiment to test for the same. When landing quickly is not an option, an alternative plan would be to depressurize the cabin, render the hijacker(s) unconscious, and then have one pilot don a portable oxygen mask and restrain the hijacker(s) before they regain consciousness. While these procedures would require new types of training, etc., the purpose of this paper is not to discuss how to implement these procedures, but instead to focus on consumer perceptions of these potential procedures.

\section{Trust}

Trust is integral in the commercial setting involving a social aspect, including the trust of a passenger in the safe operation of the flight (Davis, Lee, \& Ruhe, 2008). In the setting of the current research study, trust and willingness to fly are being judged on the passengers" perception of the system of cabin depressurization. Trust, however, can be defined in several different forms. Trust is a psychological construct. One such definition of trust that is most apt for the context of this research states that trust is defined in terms of vulnerability, it can be noted that trust lies in the faith of a positive result. Additionally, the trustor believes that the relinquishment of control to another person or object to perform what is expected is in their best interest (Mayer, et. al., 1995)=

The relationship of trust and willingness to the actual cabin depressurization system is an important facet to recognize. However, another element of the trust relationship that must be considered is the passengers' trust in the pilot/operator to safely execute the depressurization and conduct the emergency maneuvers to get the plane on the ground as soon as possible to eliminate the threat. Another form of the trust definition states that trust can be explained as the predictability of another person (Deutsch, 1958; Eckel \& Wilson, 2004; Ergeneli, Saglam, \& Metin, 2007): It is important to note however that trust is an extremely volatile function or construct and one that is deeply rooted in emotion and psychology. Slovic (1993) went as far to suggest that once trust was broken or lost, it was almost impossible to regain. 


\section{Gender Differences}

The study aims at researching differences between the participants' decisions based on gender. The two different scenarios do not necessarily differ drastically in their level of risk from an aviation expert or medical opinion point of view. However, there may be a perceived increased level of risk for the consumer when dealing with the cabin depressurization scenario. Several research studies have analyzed gender differences, including the differences in their decision-making and their risk assessment (Byrnes, Miller, \& Schafer, 1999; Powell \& Ansic, 1997; Schubert, Brown, Gysler, \& Brachinger, 1999).

A study by Powell and Ansic (1997) showed that females were less risk-seeking than males. These findings were stated to be irrespective of familiarity, costs, framing or ambiguity. The study went on to state that females adopted different strategies to make financial decisions and differed significantly to male counterparts in their risk assessment. A meta-analysis study was conducted on 150 studies analyzing risktaking tendencies of males and females. The results showed that females indicated as having less risk taking tendencies in 14 out of 16 types of tasks (Byrnes, Miller, \& Schafer, 1999). However, an anecdote stated by the study claims that the size of the risk taking differences between the genders reduced with an increase in age of the participants. Schubert, Brown, Gysler, and Brachinger (1999) state that there is evidence to suggest that females are more risk-averse than males in financial decision-making. Additionally, that study suggests that when dealing with people of the same economic status, single women are less risky than single men. With an understanding towards the mindset of female passengers, the research could have several practical implications on the aviation industry. This is important since the aviation industry is fairly male dominated field. While aviation experts are responsible for making decisions and policies, it is important for them to have the perspective of all passengers.

\section{Affect}

Hogg, Abrams, and Martin (2010) stated that affect refers primarily to feeling or emotion. Alpert and Rosen (1990) suggested that affect can have several different meanings and interpretations of emotions based on the situation. Similarly, it is important to note that Russell (2003) went on to state that at the heart of emotions are "core affect" states of feeling simply good or bad, and these states can influence reflexes, perception, cognition, and behavior. Emotions are tied into the nature in which human beings make decisions (Schwarz, 2000). Humans oftentimes allow emotions to influence their decisions, and sometime cannot eliminate the emotional factor from the decision-making process (Sayegh, Anthony, \& Perrewe, 2004). While emotional decision-making is not bad, emotions do introduce a certain level of variability (Bechara, 2004). In this study, affect was measured by the Likert-type ratings of the participants.

Lewis and Wiegert (1985) stated that interpersonal trust has cognitive and affective foundations. While trust is an important construct in understanding the research, it is possible to consider trust in the form of affect-based trust. Affect-based trust can be considered as one where sincere concern and support leads to emotional ties between individuals (McAllister, 1995). Interpersonal trust involving human-to-human trust can be interpolated to the trust between humans and machines. Similarly, affect-based trust between individuals can be translated to understand the relationship of emotional trust between humans and automation (Hughes, Rice, Trafimow, \& Clayton, 2009).

Prior research studies have used affect as the mediator of interest. Mediation analyses have been conducted to determine whether affect is a mediator to consumer perceptions (Babin, \& Attaway, 2000; Baker \& Cameron, 1996; Campbell, 2007; Rice, Winter, Kraemer, Mehta, \& Oyman, in press; Winter, Rice, \& Mehta, 2014). In several prior studies, affect has been found to mediate the relationship between the condition and the effect thereby suggesting that emotions were partially responsible for the participants" decisions. This study seeks to utilize this area of research and applies it to a scenario involving the safety of the passengers themselves. The aim of this study is geared toward determining whether affect, or emotion, plays a role in the passengers' decision to accept a cabin depressurization policy of terrorist mitigation. 


\section{Current Study}

A consumer perception study has not yet been conducted to research how passengers would feel about pilots depressurizing the cabin during a hijacking scenario. This study seeks to fill that gap in the scientific research. Participants were asked to respond to certain questions based on two different methods of dealing with hijackings. Participants provided demographic information and ratings of affect and willingness. Gender differences were also examined. A mediation analysis was employed to examine further the relationship between the pilots' actions and willingness to fly, and how that relationship might be mediated by affect. The hypotheses were as follows:

1. That participants would feel more negatively about the cabin depressurization scenario, and would be less willing to fly in these situations.

2. That there would be differences in affect and willingness ratings based on the participants' gender.

3. That affect would mediate the relationship between the type of procedure and willingness ratings of the participants.

\section{Methods}

Participants. Four hundred and forty-nine (176 females) participants from the United States participated in the study. The mean age was $35.96(S D=10.40)$. Participants were recruited via Amazon's ${ }^{\circledR}$ Mechanical Turk ${ }^{\circledR}$ (MTurk).

Procedure, Materials and Stimuli. The study was conducted using an online instrument developed with FluidSurveys ${ }^{\circledR}$. MTurk participants were first asked to fill out a consent form and then given instructions. Following this, participants were presented with information of procedures to deal with terrorist threats on a commercial airline flight. The two different scenarios were: a) the traditional scenario of preventing hijackers from accessing the flight controls, and b) an alternative scenario whereby the pilot depressurizes the cabin. Each group of participants was then asked how the scenario made them feel. Participants responded along three different Likert-type scales from extremely negative, unfavorable, bad $(-3)$ to extremely positive, favorable, good $(+3)$. There was a zero neutral option for each scale.

Following this, participants were asked a series of questions to gauge their willingness to fly in the situations. The study utilized a valid and reliable scale that was created by Rice et al. (2015). The questions for which are attached in Appendix A. Participants responded along a Likert-type scale from strongly disagree (2 ) to strongly agree $(+2)$. The mediating variables were presented temporally prior to the outcome variables, in order to avoid reverse causal effects (Kenny, 2011). Lastly, participants were asked for demographics information, debriefed and dismissed.

Design. A two-way between-participants factorial design was employed, where the independent variables were: 1) the type of policy used to deal with the hijacking (current or alternative procedure), and 2) gender of the participant. 


\section{Results}

A Cronbach's Alpha test was conducted on the affect data to determine the level of internal consistency. The values ranged from .94 to .96. Due to high internal consistency between the scores, the affect data was combined for further analyses. The same was performed for the Willingness data, as the scores ranged from .96 to .98 .

A two-way ANOVA was conducted on the affect data, with Type of Procedure, and Gender of the participants as the factors. There was a main effect of Type of Procedure, $F(1,445)=171.84, p<.001$, partialeta squared $=.28$, and Gender, $F(1,445)=10.52, p<.001$, partial-eta squared $=.02$. There was no significant interaction between Gender and Type of Procedure, $F(1,455)=0.481, p=.488$, partial-eta squared $=.001$. As Figure 1 suggests, the consumers, in general, felt more negatively about the cabin depressurization situations, while females felt much more negative about these situations as compared to the male participants.

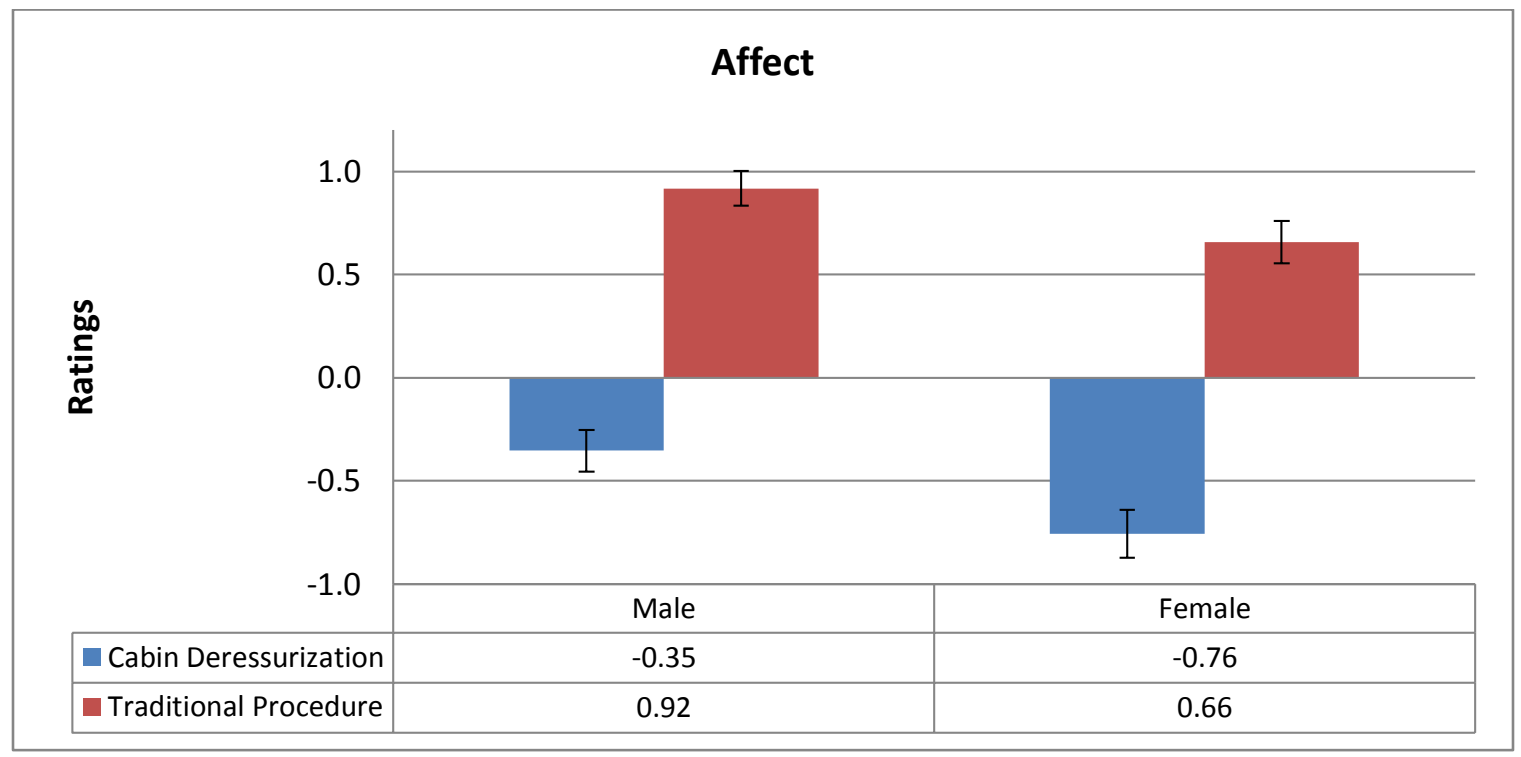

Figure 1. Affect data from the experiment. SE bars are included.

A two-way ANOVA was conducted on the Willingness data, with Type of Procedure and Gender of the participants as the factors. There was a main effect of Type of Procedure $F(1,445)=92.07, p<.001$, partial-eta squared $=.17$, and Gender, $F(1,445)=14.04, p<.001$, partial-eta squared $=.03$. There was no significant interaction between Gender and Type of Procedure, $F(1,455)=1.507, p=.220$, partial-eta squared $=.003$. As Figure 2 suggests, the consumers, in general, were less willing to fly in the cabin depressurization situations, while females were, in general, less willing to fly in these situations as compared to the male participants. 


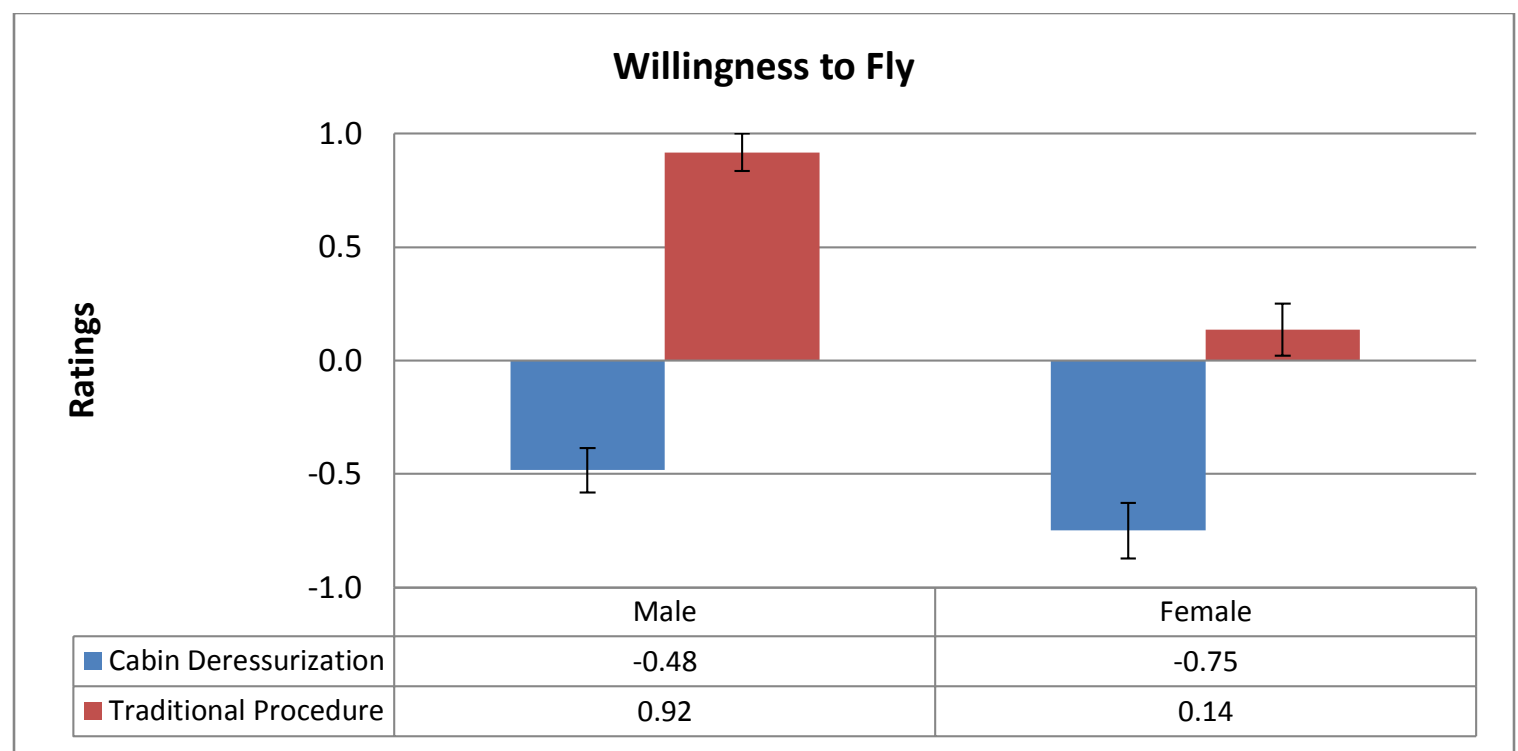

Figure 2. Willingness data from the experiment. SE bars are included.

\section{Mediation Analyses}

The mediation analysis was conducted to determine whether affect mediated the relationship between the type of procedure and willingness. The paths for these mediation analyses can be found in A and $\mathrm{B}$ in Figure 3.

A
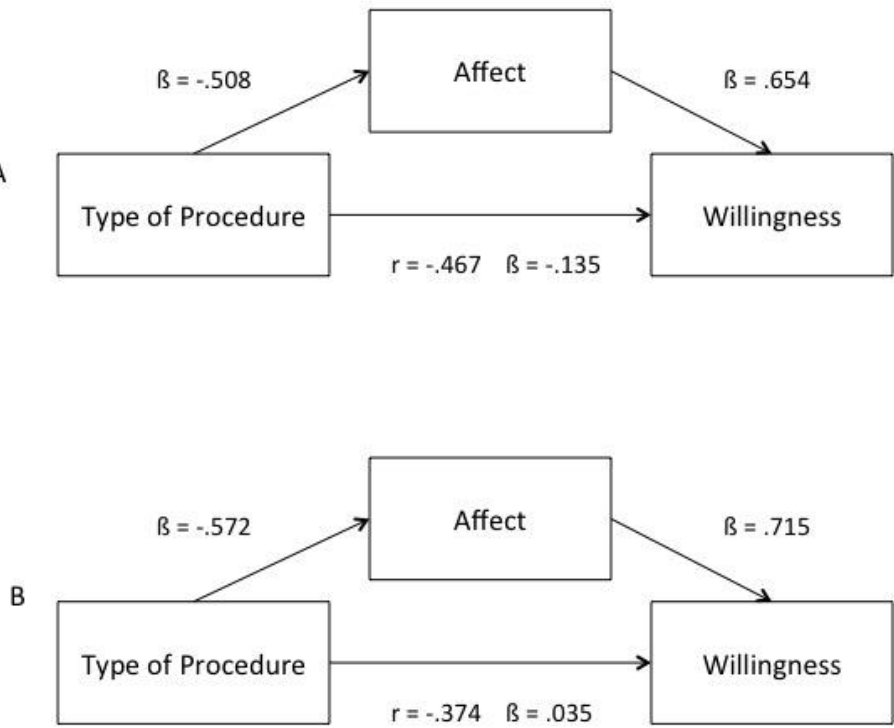

Figure 3. Paths for the mediation analysis

The first mediation analysis was conducted on the male participants. In order to conduct the mediation analysis, the correlation between Type of Procedure and willingness was first found to be significant, $r=$ $.467, p<.001$, showing that the initial variable correlated with the outcome variable. The standardized path coefficients were: Type of Procedure to affect (Beta $=-.508, p<.001)$; affect to willingness (Beta $=.654, p<$ $.001)$; Type of Procedure to willingness controlling for affect (Beta $=-.135 ; p=.005)$. The second mediation analysis was conducted on the female participants. In order to conduct the mediation analysis, the correlation 
between Type of Procedure and willingness was first found to be significant, $r=-.374, p<.001$, showing that the initial variable correlated with the outcome variable. The standardized path coefficients were: Type of Procedure to affect (Beta $=-.572, p<.001)$; affect to willingness (Beta $=.715, p<.001)$; Type of Procedure to willingness controlling for affect (Beta $=.035 ; p=.6$ ). These data show that affect had a total mediating effect on the relationship between Type of Procedure and Willingness.

\section{Discussion}

One of the goals of the commercial aviation industry is to provide safe air travel. As discussed earlier, the threat of an airliner being hijacked is one of the more serious situations that the industry needs to deal with. The purpose of this study was to compare consumers' willingness to fly on board a flight based on the method of dealing with airline hijackings. The study attempted to understand if consumers would have differing perceptions of the alternative proposed procedure of depressurizing the cabin as compared to the current policies. Additionally, the research conducted a mediation analysis to see if the relationship between the consumer's willingness and the type of policy enacted was mediated by affect.

The first hypothesis stated that the participants would be less willing and feel more negatively about the cabin depressurization scenario. The results of the study supported this prediction. The research suggests that passengers were in fact less willing to fly on board a scenario where the pilot had the authority to depressurize the cabin in the event of a hijacking scenario. Additionally, the data revealed that passengers felt much more negatively about this scenario as compared to the current policy where the pilot is required to lock the cockpit door and deny access to the flight controls. While the alternative policy addresses the issue of the safety of the passengers on board the flight during a hijacking, it does add the possibilities of physiological harm due to decreased oxygen content during a cabin depressurization. There could several possible reasons and explanations for these results. A plausible explanation for the same could suggest that passengers are unwilling due to the fear of potential physiological harm to themselves. Terrorist activity on board an airliner has been a prominent topic and fear since the attacks of 9/11. Passenger trust significantly decreased in commercial air travel as witnessed by the significant decline in air travel after the attacks (Blunk, Clark, \& McGibany, 2006). While the belief that the effects of short-term oxygen deprivation are minimal, nothing can be stated for certain. There will always remain a certain level of inherent risk. These findings are interesting as they suggest that passengers may be unwilling to test a new policy/procedure even if it may potentially make commercial airline travel significantly safer. Slimak and Dietz (2006) stated that a greater fear is associated with an unknown situation or risk that one that has been experienced before, and this may part of the explanation as to why passengers are less willing to fly on board in this scenario. The question therefore arises as to whether the risk is worth the benefit. This is one of the more valuable contributions of the research, as it provides the consumers' perspective on the question. The results suggest that the travelling public's opinion on the matter is that the potential benefits are not worth the risks involved.

The second hypothesis predicted that there would be differences in consumer ratings based on the gender of the participant. The results of the study supported the hypothesis. The analysis of gender differences revealed that females were both more negative about the cabin depressurization scenario, and much less willing to fly in that situation. One possible explanation of these differences could be founded in the same context of other studies that suggest that females are less risk-taking in several categories of decision-making (Rice et al., 2014; Winter et al., 2015). As mentioned earlier, while experts may deem there to be no significant increase in risks associated with the cabin depressurization, this may not be the same perception of the consumers.

The last hypothesis stated that affect would mediate the relationship between the types of procedure and willingness ratings of the participants. The mediation analysis supported this prediction, and showed that affect fully mediated the relationship, similar to previous research studies (Babin, \& Attaway, 2000; Baker \& Cameron, 1996; Campbell, 2007; Rice, Winter, Kraemer, Mehta, \& Oyman, in press; Winter, Rice, \& Mehta, 2014), between the type of policy/procedure to deal with hijackings and willingness to fly. This finding is 
interesting, as it appears that an emotional influence on decision-making is found to be present for the results of the willingness to fly ratings of the participants. In other words, the results suggest that the participants are basing their willingness to fly on their emotions. As mentioned earlier, humans tend to have difficulty removing emotions from their decision making process (Sayegh, Anthony, \& Perrewe, 2004; Schwarz, 2000). It is important to understand this facet, as it gives the airline industry an understanding of the mindset of the passengers, and their emotional reactions behind the same.

\section{Limitations}

No research is without certain limitations, and this study is no exception. One of the primary limitations of the study is that the participant data was collected using Amazon's ${ }^{\circledR}$ Mechanical Turk ${ }^{\circledR}$. While this source of sample data collection is fairly convenient, it is subject to the normal limitations of collecting data from human participants, and this leads to certain risk exposure related to the data. Certain studies have suggested that MTurk data is as reliable as laboratory data (Buhrmester, Kwang, \& Gosling, 2011; Germine et al., 2012). A secondary limitation of the methodology of the study is that while participants are collected using an online survey tool, the study does not prevent people from participating even if they have never been on a passenger on a commercial airline flight. Since this is a consumer perception study, it is important to list this limitation when making generalizable claims since some participants may not truly be commercial airline consumers.

Another layer of consideration that must be paid attention to is that the study compensated participants for the completion of the survey, and this may have had an influence on the mindset of the participant. While dealing with economics, it must be mentioned that financial support and funding were limited for the study. For this reason, the minimum number of participants required was utilized. Lastly, while these results are interesting, they only represent participants from the United States of America. Aviation being a global industry, it is unfair to make generalizable claims to the entire industry, and therefore the entire world based on the findings of this study.

\section{Practical Implications}

The results of the research study are of value and interest to the aviation industry, and policy makers specifically. Industry experts have the technical knowledge and understanding of aviation, and so are rightfully tasked with developing and implementing policies and procedures that are the safest and most efficient. Conversely, aviation is a consumer-oriented field, and consumer perceptions are of value and interest as well. Understanding the mindset of the travelling public can be very insightful when making decisions. This study suggests that while the alternative procedure may provide a safer environment for the passengers on board the flight (at least from a security perspective), they are less willing to fly on board the flight in such a scenario. This could be a heavily influencing factor in the aviation industry's final decision to implement the proposed alternative of cabin depressurization during hijackings.

\section{Future Research}

This study appears to be the first to understand consumer perceptions on cabin depressurization as a potential means of dealing with hijackings. This research lays a foundation for future research to continue to examine this are of aviation and gain a deeper understanding of the reasons and willingness of passengers to fly on board different scenarios. While the foundation has been laid, this study focuses on only on alternative procedure. If newer, less aggressive alternatives are thought up or developed; future research could use this study as a template to understand consumer willingness to fly on flights using those procedures.

While this research does provide some interesting results, this study only collects data from the United States. In order to get an accurate representation of the global aviation industry, future research should seek to collect data from other countries around the world. Additionally, future research may seek to 
collect more demographic data from participants to identify certain predictive characteristics that could affect consumer willingness.

\section{Conclusions}

The purpose of this study was to understand the consumers' perception of alternative procedures to dealing with hijackings. While depressurizing a cabin does seem excessive and an aggressive approach, it does have potential to be a means of providing a safer and secure environment for all parties involved. However, the results of the study suggest that passengers are much less willing to fly on board flights employing such a policy, and overall feel much more negatively towards these scenarios. Consumer perceptions are an important part of the consumer-oriented field of aviation, and future studies along this line of research could provide more detailed understandings of the overall mindset of a passenger as it relates to different spheres of commercial air travel. 


\section{References}

9/11 Commission. (2004). Final report of the national commission on terrorist attacks upon the United States. Washington, DC: US Government.

Alpert, M., \& Rosen, A. (1990). A semantic analysis of the various ways that the terms "affect,"“emotion," and "mood" are used. Journal of Communication Disorders, 23(4), 237-246.

Babin, B. J., \& Attaway, J. S. (2000). Atmospheric affect as a tool for creating value and gaining share of customer. Journal of Business Research, 49(2), 91-99.

Baker, J., \& Cameron, M. (1996). The effects of the service environment on affect and consumer perception of waiting time: An integrative review and research propositions. Journal of the Academy of Marketing Science, 24(4), 338-349.

Bechara, A. (2004). The role of emotion in decision-making: evidence from neurological patients with orbitofrontal damage. Brain and Cognition, 55(1), 30-40.

Blunk, S. S., Clark, D. E., \& McGibany, J. M. (2006). Evaluating the long-run impacts of the $9 / 11$ terrorist attacks on US domestic airline travel. Applied Economics, 38(4), 363-370.

Buhrmester, M., Kwang, T., \& Gosling, S. D. (2011). Amazon's Mechanical Turk: A new source of inexpensive, yet high-quality data? Perspectives on Psychological Science, 6(3), 3-5.

Byrnes, J. P., Miller, D. C., \& Schafer, W. D. (1999). Gender differences in risk taking: A metaanalysis. Psychological Bulletin, 125(3), 367.

Campbell, M. C. (2007). "Says who?!" How the source of price information and affect influence perceived price (un) fairness. Journal of Marketing Research, 44(2), 261-271.

Castella, T. (2015). Who, What, Why: How are cockpit doors locked? BBC News. 26 Mar. 2015. http://www.bbc.com/news/blogs-magazine-monitor-32070528

Davis, J. H., Lee, M., \& Ruhe, J. (2008). Trust: An intercultural comparison of consumer perceptions. International Journal of Commerce \& Management, 18(2), 150-165.

Deutsch, M. (1958). Trust and suspicion. The Journal of Conflict Resolution, 2, 265-279.

Eckel, C. C. \& Wilson, R. K. (2004). Is trust a risky decision? Journal of Economic Behavior \& Organization, 55, 447-465.

Ergeneli, A., Saglam, G., \& Metin, S. (2007). Psychological empowerment and its relationship to trust in immediate managers. Journal of Business Research, 60, 41-49.

Germine, L., Nakayama, K., Duchaine, B.C., Chabris, C.F., Chatterjee, G., \& Wilmer, J.B. (2012). Is the web as good as the lab? Comparable performance from web and lab in cognitive/perceptual experiments. Psychonomic Bulletin \& Review, 19(5), 847-857.

Hogg, M.A., Abrams, D., \& Martin, G.N. (2010). Social cognition and attitudes. In Martin, G.N., Carlson, N.R., \& Buskist, W., (Eds.), Psychology (pp. 646-677). Harlow: Pearson Education Limited.

Holden, R. T. (1986). The contagiousness of aircraft hijacking. American Journal of Sociology, 91(4), 874-904.

Hughes, J., Rice, S., Trafimow, D. \& Clayton, K. (2009). The automated cockpit: A comparison of attitudes towards human and automated pilots. Transportation Research Part F: Traffic Psychology and Behaviour, 12(5). 428-439.

Jansen, B. (2015). Locking the Cockpit: How Airline Security Varies. USA Today. N.p., 27 Mar. 2015. http://www.usatoday.com/story/news/2015/03/26/cockpit-locks-pilots-airbus/70481560/

Kenny, D. A. (2011). Mediation. Retrieved from http://davidakenny.net/cm/mediate.htm\#D on Feb 28, 2012.

Landes, W. M. (1978). An economic study of US aircraft hijacking, 1961-1976. Journal of Law and Economics, $21(1), 1-31$.

Lewis, J. D., \& Weigert, A. 1985. Trust as a social reality. Social Forces, 63, 967-985.

Mayer, R. C., Davis, J. H., \& Schoorman, F. (1995). An integrative model of organizational trust. Academy of Management Review, 20(3), 709-734. Doi:10..5465/AMR.1995.9508080335

McAllister, D.J. (1995) Affect- and cognition-based trust as foundations for interpersonal cooperation in organizations. Academy of Management Journal, 38, 24-59.

Powell, M., \& Ansic, D. (1997). Gender differences in risk behaviour in financial decision-making: An experimental analysis. Journal of Economic Psychology, 18(6), 605-628. 
Rice, S., Kraemer, K., Winter, S. R., Mehta, R., Dunbar, V., Rosser, T. G., \& Moore, J. C. (2014). Passengers from India and the United States have differential opinions about autonomous auto-pilots for commercial flights. International Journal of Aviation, Aeronautics, and Aerospace, 1(1). Retrieved from http://commons.erau.edu/ijaaa/vol1/iss1/3

Rice, S., Mehta, R., Dunbar, V., Oyman, K., Ghosal, S., Oni, M.D. \& Oni, M.A. (2015, January). A valid and reliable scale for consumer willingness to fly. Proceedings of the 2015 Aviation, Aeronautics, and Aerospace International Research Conference.

Rice, S., Winter, S.R., Kraemer, K., Mehta, R. \& Oyman, K. (in press). How do depression medications taken by pilots affect passengers' willingness to fly? A mediation analysis. Review of European Studies.

Russell, J. A. (1980). A circumplex model of affect. Journal of Personality and Social Psychology, 39(6), 1161-1178.

Sayegh, L., Anthony, W. P., \& Perrewe, P. L. (2004). Managerial decision-making under crisis: The role of emotion in an intuitive decision process. Human Resource Management Review, 14(2), 179-199.

Schubert, R., Brown, M., Gysler, M., \& Brachinger, H. W. (1999). Financial decision-making: are women really more risk-averse? American Economic Review, 89(2), 381-385.

Schwarz, N. (2000). Emotion, cognition, and decision making. Cognition \& Emotion, 14(4), 433-440.

Slimak, M. W., \& Dietz, T. (2006). Personal values, beliefs, and ecological risk perception. Risk. Analysis, 26(6), 1689-1705.

Slovic, P. (1993). Perceived Risk, Trust, and Democracy. Risk. Analysis, 13, 675-682. doi: 10.1111/j.15396924.1993.tb01329.x

Winter, S. R., Rice, S., \& Mehta, R. (2014). Aviation consumers' trust in pilots: A cognitive or emotional function. International Journal of Aviation, Aeronautics, and Aerospace, 1(1). Retrieved from http://commons.erau.edu/ijaaa/vol1/iss1/2

Winter, S. R., Rice, S., Mehta, R., Cremer, I., Reid, K. M., Rosser, T. R., \& Moore, J. C. (2015). Indian and American consumer perceptions of cockpit configuration. Journal of Air Transport Management, 42, 226231. 


\section{Appendix A}

\section{Willingness to Fly Scale}

(Rice et al., 2015)

"I would be happy to fly in this situation"

Strongly disagree Disagree Neutral Agree

Strongly agree

"I would be willing to fly in this situation"

Strongly disagree Disagree Neutral Agree Strongly agree

"I have no fears of flying in this situation"

Strongly disagree Disagree Neutral Agree Strongly agree

"I would be comfortable flying in this situation"

Strongly disagree Disagree Neutral Agree Strongly agree

"I would have no problem flying in this situation"

Strongly disagree Disagree Neutral Agree Strongly agree

"I feel confident flying in this situation"

Strongly disagree Disagree Neutral Agree Strongly agree

"I would feel safe flying in this situation"

Strongly disagree Disagree Neutral Agree Strongly agree 